\title{
Letter to the editor concerning: 'Correlation between clinical findings and eosinophil/neutrophil ratio in patients with nasal polyps'
}

\author{
Satvinder Singh Bakshi ${ }^{1,2}$
}

Received: 9 May 2015/Accepted: 25 May 2015/Published online: 18 June 2015

(C) Springer-Verlag Berlin Heidelberg 2015

Dear Editor,

The article 'Correlation between clinical findings and eosinophil/neutrophil ratio in patients with nasal polyps' by Hancer Tecimer et al. [1] is very interesting and well written. It, however, does provoke some controversy, which I would like to highlight. There is a slight flaw in the study design, which may have affected the results of the study. The groups differ in the treatment they have received, that is, the number of patients who underwent surgery or continued medical treatment in both the groups are different, and this creates a 'Treatment Bias', which can affect the outcome of the study. There are also few unanswered questions like 'Did the same surgeon operate all the patients?', 'Was the endoscopic grading done by the same person?' There have been many studies, which have proven that presence of eosinophils is an adverse factor and correlates with higher recurrence of polyps and a worse outcome after surgery [2-4]. The equivocal result in this study may be due to a smaller sample size and the treatment bias of both the groups. The best way forward would be design

This comment refers to the article available at doi:10.1007/s00405-014-3174-4.

An author's reply to this comment is available at doi:10.1007/s00405-015-3686-6.

Satvinder Singh Bakshi

saty.bakshi@gmail.com

1 Department of ENT and Head and Neck Surgery, Mahatma

Gandhi Medical College and Research Institute,

Pillaiyarkuppam, Pondicherry 607402, India

2 House Number B2, Shree Pushpa Complex, 15th Bharathi Street, Ananda Nagar, Pondicherry 605009, India a blinded randomized control trial in which both the groups receive the same treatment and are followed for at least a year, before a definite conclusion can be arrived.

Conflict of interest None.

\section{References}

1. Hancer Tecimer S, Kasapoglu F, Demir UL, Ozmen OA, Coskun H, Basut O (2015) Correlation between clinical findings and eosinophil/neutrophil ratio in patients with nasal polyps. Eur Arch Otorhinolaryngol 272(4):915-921

2. Grgić MV, Ćupić H, Kalogjera L, Baudoin T. Surgical treatment for nasal polyposis: predictors of outcome. Eur Arch Otorhinolaryngol [Epub ahead of print]

3. Sun DI, Joo YH, Auo HJ, Kang JM (2009) Clinical significance of eosinophilic cationic protein levels in nasal secretions of patients with nasal polyposis. Eur Arch Otorhinolaryngol 266(7):981-986

4. Nakayama $T$ et al (2011) Mucosal eosinophilia and recurrence of nasal polyps-new classification of chronic rhinosinusitis. Rhinology 49(4):392-396 